\title{
ISLAM DAN MODERASI BERAGAMA DALAM PERSPEKTIF HADITS
}

\author{
FAELASUP \\ STAI Sangatta Kutai Timur

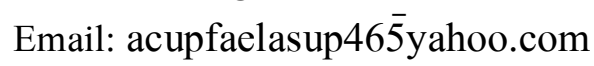

\begin{abstract}
Abstrak
Moderasi beragama merupakan sikap toleran dan mengenal kompromi dalam melihat perbedaan. Penelitian ini menginventarisir hadits-hadits yang berkaitan dengan moderasi beragama dengan kata وسطيه yang berarti moderasi. Dari penelusuran كتب التسعة tidak ditemukan kata وسطيه, namun terdapat beberapa kata yang sepadan dengan وسطيه yaitu

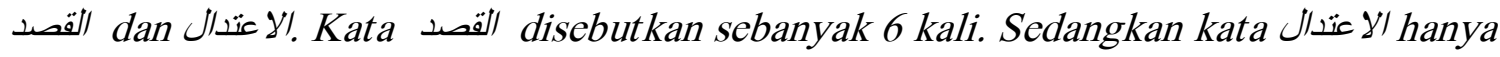
satu kali terdapat pada hadits Tirmidzi hadits ke 255. Prinsip wasathiyah yang diterangkan dalam hadits adalah Al-khairiyah (terpilih atau terbaik), Al-'adalah (sikap adil), Al-Tawazun (kesimbangan). Attasamuh (toleran). Al-Istiqamah (Konsistensi), Raf al-halaj (menghilangkan kesulitan).
\end{abstract}

\section{Kata Kunci}

Islam, Moderasi Beragama, Hadits

\begin{abstract}
Religious moderation is a tolerant attitude and recognizes compromise in seeing differences. This research makes an inventory of the hadiths related to religious

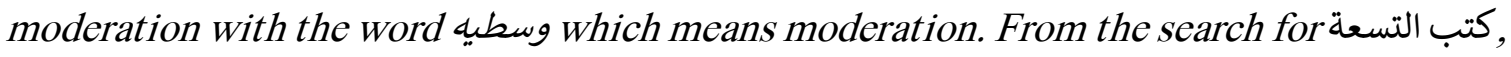
the word وسطيه was not found, but there are several words that are equivalent to namely القصد is mentioned 6 times. Meanwhile, the word الاعتدال is only found once in the 255th Hadith Tirmidhi. The principle of wasathiyah described in the hadith is Al-khairiyah (chosen or best), Al-'adalah (fair attitude), AlTawazun (balance). Attasamuh (tolerant). Al-Istiqamah (Consistency), Raf al-halaj (eliminating difficulties).
\end{abstract}

\section{Keywords}

Islam, Religious Moderation, Hadith

\section{Pendahuluan}

Pembahasan tentang moderasai (wasatiyah) beragama kian hari kian santer dibicarakan di kalangan kaum pelajar, ilmuan, ataupun budayawan serta pemerhati agama. Istilah moderat (wasatiyah) merupakan karakteristik ajaran Islam, yaitu dengan cara mengambil jalan tengah. Sikap berlebihan dalam menentukan keputusan hanya akan menimbulkan permasalahan yang tidak akan selesai. Dalam hal ini Islam dan pemeluknya menghadapi dua masalah, yaitu: pertama kecenderungan sebagian kalangan ummat Islam untuk bersikap ekstrem dan ketat dalam 
memahami teks-teks keagamaan dan mencoba memaksakan cara-cara tersebut di tengah masyarakat muslim, bahkan dalam beberapa hal menggunakan kekerasan, kedua: kecenderungan lain yang juga ekstrem dengan bersikap longgar dalam beragama dan tunduk pada perilaku serta pemikiran negatif yang berasal dari budaya dan peradaban lain.

Moderasi beragama merupakan sebuah jalan tengan di tengah keberagaman agama di Indonesia. Dalam konteks beragama, memahami teks agama saat ini terjadi kecenderungan terpolarisasinya pemeluk agama dalam dua kutub ekstrem. Satu kutub terlalu mendewakan teks tanpa menghiraukan sama sekali kemampuan akal/nalar. Teks kitab suci dipahami lalu diamalkan tanpa memahami konteks. Beberapa kalangan menyebut kutub ini adalah sebagai golongan konservatif. Kutub ekstrem yang lain sebaliknya, yang sering disebut kelompok liberal, terlalu mendewakan akal pikiran sehingga mengabaikan teks itu sendiri. ${ }^{1}$ Moderasi harus dipahami ditumbuhkembangkan sebagai komitmen bersama untuk menjaga keseimbangan yang paripurna, dimana setiap warga masyarakat, apapun suku, etnis, budaya, agama dan pilihan politiknya, mau mendengarkan satu sama lain serta saling melatih menjaga kemampuan mengelola dan mengatasi perbedaan di antara kita.

Sikap tawasuth yang berintikan pada prinsip hidup yang menjunjung tinggi dan mengharuskan adil dan lurus di tengah-tengah kehidupan bersama bertindak lurus dan selalu sifat membangun serta menghindari segala bentuk pendekatan yang bersifat tathorruf (ekstrem). ${ }^{2}$ Penerapan sikap tawasuth bukan berarti menerima semuanya dan mencampuradukkan semua unsur (sinkrestisme).

At tawasuth dalam Islam adalah titik tengah di antara dua ujung, dan dua hal tersebut merupakan kebaikan yang diberikan Allah swt. Prinsip dan karakter tawasuth yang sudah menjadi karakter Islam ini harus diterapkan di segala bidang, supaya agama Islam sikap dan tingkah laku ummatnya selalu menjadi saksi dan pengukuran kebenaran bagi semua sikap dan tingkah laku manusia pada umumnya. ${ }^{3}$ Menurut As'ad Thoha, ada beberapa hal yang harus diperhatikan dalam penerapan tawasuth yaitu:

1. Tidak bersikap ekstrem dalam menyebarkan ajaran ahlussunnah wal jama'ah

2. Tidak mudah mengkafirkan sesame muslim karena perbedaan pemahaman agama.

3. Memposisikan diri dalam kehidupan bermasyarakat dengan senantiasa memegang teguh prinsip persudaraan (ukhuwah) dan toleransi, hidup berdampingan baik dengan sesama warga NU, sesama umat Islam maupun warga negara yang memeluk agama lain. ${ }^{4}$

Prinsip tawasuth di dalam Islam terdiri atas beberapa hal dan kesemuanya merupakan cakupan dari konsep dasar Islam, yakni konsep aqidah, Syariah, dan akhlak.

\footnotetext{
${ }^{1}$ Agus Akhmadi, Moderasi Beragama Dalam Keragaman Indonesia, Jurnal Diklat Keagamaan, Vol. 13, no. 2, Pebruari - Maret 2019

${ }^{2}$ Nurcholis, Ahlussunnah Wal Jama'ah Dan Nahdlatul Ulama. (Tulungagung: PC NU KAB. Tulungagung, 2011), hal, 96

${ }^{3}$ Achmad Siddiq, Khittoh Nahdliyin Cet. III, (Surabaya: Khalista LTNU, 2005), hlm. 62-63.

${ }^{4}$ As'ad Thoha, Pendidikan Aswaja dan ke-NU-an untuk MA/SMA/SMK kelas 12 Kurikulum 2012, (Jawa Timur: PWLP Ma'arif NU 2013), hlm. 11
} 


\section{Tawasuth bidang Aqidah}

Aqidah merupakan pondasi awal bagi setiap orang Islam untuk meyakini keesaan Allah dengan segala sifat dan qudrat iradat-Nya. Sebagai agama yang sempurna, Islam memberikan nilai-nilai ajarannya supaya selalu berada di tengah-tengah (tawasuth) serta tidak menyalahkan pihak lain. Dalam tawasuth bidang aspek aqidah, dapat dilihat hal-hal berikut:

a. Ketuhanan antara Atheisme dan Poletheisme

Islam ada di antara Atheisme yang mengingkari adanya tuhan dan politheisme yang mempercayai banyak tuhan. Artinya Islam tidak mengambil paham atheism atau politheisme, melainkan paham monotheisme yakni paham yang mempercayai Tuhan Yang Maha Esa.

b. Alam antara khayalan dan kenyataan

Islam memiliki watak moderat menempatkan dirinya diantara pandangan yang mempercayai tidak adanya wujud selain alam nyata dan pandangan bahwa alam ini hanya sebuah hayalan yang tidak memiliki hakikat wujud sebenarnya. Bagi Islam, ala mini merupakan hakikat yang tidak bias diragukan, namun di balik itu ada hakikat lain yaitu Dzat Yang Menciptakannya dan mengat urnya.

c. Sifat Allah antara Ta'thil dan Tasyib

Ada sebagian paham yang tidak mempercayai adanya sifat bagi Allah. Menurut paham ini, Allah tidak memiliki sifat apapun, yang ada hanyalah dzat. Dipihak lain ada paham yang menyipati Allah dengan sifat-sifat yang serupa dengan sifat hawadits (makhluknya). Islam di tengah-tengah antara dua paham tersebut, yaitu menetapkan sifat-sifat yang layak bagi kemahabesaran Allah, sebagaimana tersebut di dalam al-Qur'an dan Assunnah.

d. Kenabian antara kultus dan ketus

Dalam catatan sejarah terdapat dua kelompok yang memiliki paham dan perlakuan berlebihan terhadap kenabian. Ada golongan yang mengkultus nabi setinggi-tingginya, sehingga menyamai martabat ke-Tuhan-an atau memosisikan mereka sebagai anak tuhan; dan kalangan lain yang merendahkan martabat kenabian dengan melecehkan, memfitnah, menyiksa, dan menuduh mereka sebagai pembohong. Bagi Islam para nabi adalah manusia biasa yang makan, minum, kawin, dan berjalan di pasar sebagaimana layaknya manusia biasa. Yang membedakan mereka dengan manusia biasa adalah mereka mendapatkan wahyu dari Allah swt.

e. Sumber kebenaran antara akal dan wahyu

Islam adalah agama di antara kalangan yang mempercayai akal sebagai satu-satunya sumber dan alat untuk menemukan hakikat wujud, dan kalangan lain yang memandang bahwa wahyu adalah jalan satu-sat unya untuk mendapatkan hakikat wujud. ${ }^{5}$ Bagi Islam akal dan wahyu merupakan dua hal yang sama-sama memiliki peranan penting yang sifatnya komplementer (saling mendukung ant ara satu dengan lain). Kalau diibaratkan pengadilan, akal berfungsi sebagai syahid (saksi) sementara wahyu sebagai hakim, atau sebaliknya, yakni akal sebagai hakim sementara wahyu sebagai syahid, hal ini seperti dikatakan al-Ghazali. ${ }^{6}$

\footnotetext{
${ }^{5}$ Achmad Yusuf, Moderasi Islam dalam Dimensi Trilogi Islam (Akidah, Syariah, Dan Tasawuf), Jurnal al-Murabbi, Volume 3 Nomor 1, Juni 2018

${ }^{6}$ Muhammad Al-Ghazali, Qudza'if al-Haqq, cet ke-1, (Dimisyqa: Dar al Qalam, 1991), hlm. 19
} 
2. Tawasuth bidang Ibadah

Tawasuth dalam bidang ibadah adalah mempermudah dalam menjalankan ibadah dan kewajiban hukum, ringan dan praktiknya. Hal ini tent unya sesuai dengan nash syariah yang kuat dan tentunya tidak membutuhkan penafsiran atau pentakwilan lagi. Dalam surat al-Baqoroh ayat 185 Allah berfirman:

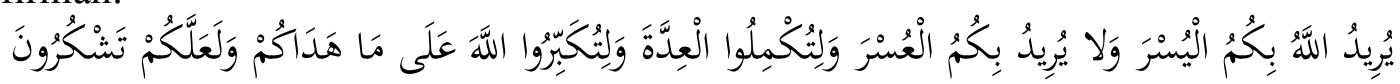

Artinya:

Allah menghendaki kemudahan bagimu, dan tidak menghendaki kesukaran bagimu. Dan hendaklah kamu mencukupkan bilangannya dan hendaklah kamu mengagungkan Allah atas petunjuk-Nya yang diberikan kepadamu, supaya kamu bersyukur.

Juga disebutkan dalam surat An-Nisa 28:

Artinya:

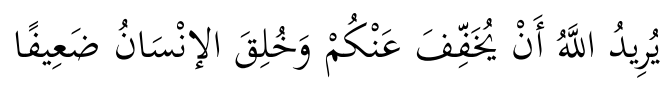

Allah hendak memberikan keringanan kepadamu, dan manusia dijadikan bersifat lemah.

Islam adalah agama yang mudah dan tidak mempersulit ummatnya. Contoh; bila seseorang tidak sanggup melakukan ibdah dengan sempurna maka ada keringanan-keringanan yang boleh dilakukan. Seperti seseorang yang tidak mampu melakukan sholat dengan berdiri maka diperbolehkan melaksanakan sholat dengan duduk atau berbaring, jika berbaring juga tidak mampu maka sukup dengan isyarat mata atau dalam hati.

Dalam surat al-Baqoroh 286 Allah berfirman:

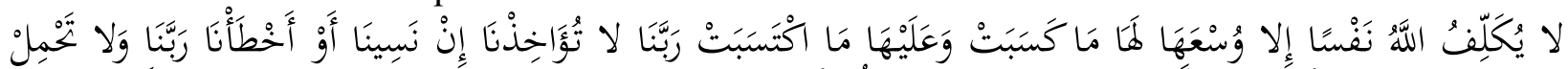

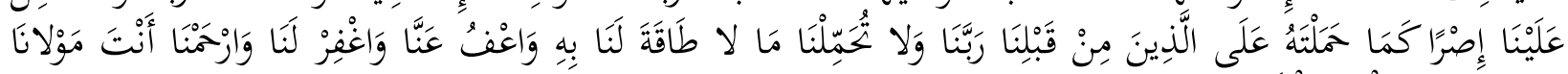

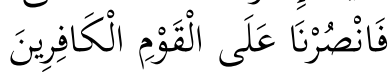

Artinya:

Allah tidak membebani seseorang melainkan sesuai dengan kesanggupannya. Ia mendapat pahala (dari kebajikan) yang diusahakannya dan ia mendapat siksa (dari kejahatan) yang dikerjakannya. (Mereka berdoa): "Ya Tuhan kami, janganlah Engkau hukum kami jika kami lupa atau kami tersalah. Ya Tuhan kami, janganlah Engkau bebankan kepada kami beban yang berat sebagaimana Engkau bebankan kepada orang-orang yang sebelum kami. Ya Tuhan kami, janganlah Engkau pikulkan kepada kami apa yang tak sanggup kami memikulnya. Beri maaflah kami; ampunilah kami; dan rahmatilah kami. Engkaulah Penolong kami, maka tolonglah kami terhadap kaum yang kafir".

3. Tawasuth bidang akhlak

Pada aspek akhlak-tasawuf, moderasi Islam dapat digambarkan dengan sikap tengah:

a. Antara Hakikat dan syariat

Dalam mememecahkan suatu persoalan, tasawuf tidak hanya menggunakan kacamata syariat atau sayariat saja, akan tetapi menggunakan kedua-duanya. Karena hakikat tanpa syariat adalah kepalsuan, dan hakikat tanpa syariat merupakan omong kosong dan cenderung permissive terhadap kejahatan dan kedzaliman. 


\section{b. Antara Khaufdan roja'}

Tasawuf mengajarkan perlunya keseimbangan antara khauf (rasa takut) dan roja' (harapan), karena khauf yang berlebihan gampang membuat orang put us asa, sedangkan roja' yang berlebihan menjadikan orang berani berbuat dosa.

c. Antara jasmaniyah dan rohaniyah

Tasawuf dimaksudkan untuk mensucikan hati dan meningkatkan kualitas ruhaniyah, namun tetap harus memperhatikan aspek-aspek jasmaniyah, seperti kekuatan fisik, kebersihan dan kesehatan.

d. Antara dhahir dan batin

Tasawuf memperhatikan aspek dhahir dan batin, seperti shalat misalnya, mempunyai format dhahir dan format batin. Format batin pada shalat adalah takbir, membaca fatihah, ruku, sujud, dan lain-lain, sedangkan format batin adalah khusyuk dan tadaru', dimana keduanya ditegakkan di hadapan Allah swt.

\section{Inventarisir Hadits-hadits Tentang Islam dan Moderasi Beragama}

Dalam beberapa literatur hadits, hampir tidak ditemukan kata وسطيه yang berarti moderasi. Hanya ada satu dalam kitab Jâmi 'al-UṢ̂̂l fî Ahââith al-Rasûl yang ditulis Ibn al-Athîr, جير الامر اوسطها (sebaik-baik perkara adalah pertengahan). ${ }^{7}$ Demikian juga al-Baihaqy dalam aljami li su'ab al-iman dengan lafad yang berbeda yaitu جير الاعمال اوسطها (sebaik-baik perbuatan

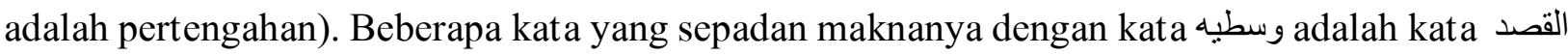
yang memiliki padanan kata الاعتدال dang juga bermakna pertengahan.

Dalam penelusuran beberapa kitab hadits, terdapat beberapa makna yang sepadan artinya dengan kata وسطيه laitu kata الاعتدال dan seperti diuraikan sebagai berikut:

Tabel 1 Pencarian lafad القصد pada beberapa kitab hadits

\begin{tabular}{|c|c|c|c|}
\hline No & Nama Kitab & Jumlah & Nomor \\
\hline 1 & Al Adabul Mufrad & $\underline{1 \text { hadis }}$ & [694] \\
\hline 2 & Doa Thabarani & 2 hadis & {$[\underline{646}][\underline{647]}$} \\
\hline 3 & Faidhul Qadir & 7 hadis & $\begin{array}{l}{[\underline{397]}[\underline{1546}][\underline{2820}][\underline{3024}][\underline{4372]}[\underline{5574}]} \\
{[\underline{7852}]}\end{array}$ \\
\hline
\end{tabular}

Tabel 2 Pencarian lafad التوسط pada beberapa kitab hadits

\begin{tabular}{clll} 
No & \multicolumn{1}{c}{ Nama Kitab } & \multicolumn{1}{c}{ Jumlah } & \multicolumn{1}{c}{ Nomor } \\
1 & Al Adabul Mufrad & $\underline{1 \text { hadis }}$ & {$[\underline{694}]$} \\
2 & Aunul Mabud & $\underline{22 \text { hadis }}$ & {$[\underline{30}][\underline{45}][\underline{60}][\underline{83}][\underline{84}][\underline{99}][\underline{113}][\underline{119}]$} \\
& & & {$[\underline{121}][\underline{123}][\underline{124}][\underline{133}][\underline{136}][\underline{143}][\underline{152}]$} \\
& & {$[\underline{158}][\underline{323}][\underline{1305}][\underline{1797}][\underline{4632}][\underline{4674}]$} \\
& & {$[\underline{4932}]$} \\
3 & Doa Thabarani & $\underline{2 \text { hadis }}$ & {$[\underline{646}][\underline{647}]$}
\end{tabular}

\footnotetext{
${ }^{7}$ Al-Mubârak b. Muhammad al-Jazarî Majd al-Dîn Abû al-Sa‘âdât b. al-Athîr, Jâmi‘ alUṣûl fî Ahâdîth al-Rasûl, ed. ‘Abd al-Qâdir al-Arnaût, Vol. 10 (Beirut: Maktabah Dâr alBayân, 1972), 130
} 


\begin{tabular}{|c|c|c|c|}
\hline \multirow[t]{5}{*}{4} & \multirow[t]{5}{*}{ Faidhul Qadir } & \multirow[t]{5}{*}{27 hadis } & [6] [257] [396] [1197] [1347] [1370] [1546] \\
\hline & & & [1637] [1677] [2129] [2277] [2377] [2431] \\
\hline & & & 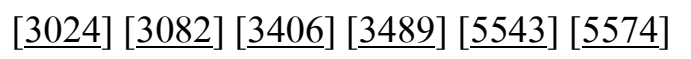 \\
\hline & & & [6016] [ 6551] [6915] [ 6990] [7852] [8319] \\
\hline & & & 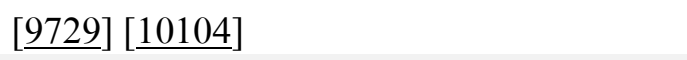 \\
\hline 5 & Fathul Bari Ibnu Hajar & $\underline{4 \text { hadis }}$ & {$[\underline{62}][\underline{5813}][\underline{5878}][\underline{8271}]$} \\
\hline 6 & $\begin{array}{l}\text { Hasyiatus Sindi Ibnu } \\
\text { Majah }\end{array}$ & $\underline{2 \text { hadis }}$ & {$[\underline{1124}][\underline{1263}]$} \\
\hline 7 & Hasyiatus Sindi Nasai & $\underline{6 \text { hadis }}$ & {$[\underline{372}][\underline{721}][\underline{883}][\underline{1084}][\underline{2315}][\underline{3039}]$} \\
\hline 8 & $\begin{array}{l}\text { Mirqatul Mafatih Ali } \\
\text { Al Qari }\end{array}$ & $\underline{22 \text { hadis }}$ & $\begin{array}{l}{[\underline{53}][\underline{64}][1318][\underline{1836}][\underline{3073}][\underline{3101}]} \\
{[\underline{3185}][\underline{3393}][\underline{3502}][\underline{3575}][\underline{3643}][\underline{3659}]} \\
{[\underline{4114}][\underline{5234}][\underline{6129}][\underline{6142}][\underline{6972}][\underline{6973}]} \\
{[\underline{7011}][\underline{7052}][\underline{7370}][\underline{8379}]}\end{array}$ \\
\hline 9 & $\begin{array}{l}\text { Mustadrak Hakim } \\
\text { Arab }\end{array}$ & $\underline{1 \text { hadis }}$ & {$[\underline{5760}]$} \\
\hline 10 & Riyadhus Shalihin & $\underline{1 \text { hadis }}$ & [121] \\
\hline 11 & $\begin{array}{l}\text { Riyadhus Shalihin } \\
\text { Arab }\end{array}$ & $\underline{1 \text { hadis }}$ & [432] \\
\hline 12 & $\begin{array}{l}\text { Syarh Shahih Muslim } \\
\text { Nawawi }\end{array}$ & $\underline{2 \text { hadis }}$ & {$[\underline{1504}][\underline{2405}]$} \\
\hline 13 & Tuhfatul Ahwadzi & $\underline{5 \text { hadis }}$ & [823] [970] [2864] [3219] [3929] \\
\hline
\end{tabular}

Tabel 3 Pencarian lafad الاعندال pada beberapa kitab hadits

\begin{tabular}{|c|c|c|c|}
\hline No & Nama Kitab & Jumlah & Nomor \\
\hline 1 & Al Adabul Mufrad & 1 hadis & [694] \\
\hline \multirow[t]{4}{*}{2} & Aunul Mabud & 25 hadis & [710] [761] [768] [769] [787] [796] [837] \\
\hline & & & [852] [853] [854] [855] [856] [858] [866] \\
\hline & & & [885] [888] [957] [1247] [2185] [3541] \\
\hline & & & {$[3588][3744][4727][4743][5010]$} \\
\hline 3 & Doa Thabarani & 2 hadis & {$[646][647]$} \\
\hline \multirow[t]{7}{*}{4} & Faidhul Qadir & 40 hadis & [19] [130] [239] [329] [402] [462] [474] \\
\hline & & & [498] [519] [872] [963] [1145] [1604] \\
\hline & & & [1619] [1902] [1942] [2236] [2390] [2464] \\
\hline & & & [2518] [2653] [2692] [2834] [3024] [3482] \\
\hline & & & {$[3952][4780][5385][5601][6532][6551]$} \\
\hline & & & [6873] [6990] [6991] [7472] [7899] [8422] \\
\hline & & & {$[8578][9813][9905]$} \\
\hline \multirow[t]{4}{*}{5} & Fathul Bari Ibnu Hajar & 33 hadis & [1029] [1049] [1098] [1172] [1178] [1179] \\
\hline & & & [1180] [1186] [1188] [1189] [1190] [1191] \\
\hline & & & [1194] [1195] [1215] [1219] [1228] [1274] \\
\hline & & & [1435] [1491] [1503] [1846] [4530] [7683] \\
\hline
\end{tabular}




\begin{tabular}{|c|c|c|c|}
\hline & & & $\begin{array}{l}{[7715][7926][8202][8433][8595][8772]} \\
{[9723][9905][9981]}\end{array}$ \\
\hline 6 & $\begin{array}{l}\text { Hasyiatus Sindi Ibnu } \\
\text { Majah }\end{array}$ & 4 hadis & [249] [2890] [3030] [3291] \\
\hline 7 & Hasyiatus Sindi Nasai & 4 hadis & [354] [1096] [2936] [3092] \\
\hline 8 & Hilyatul Aulia & 1 hadis & {$[16520]$} \\
\hline 9 & $\begin{array}{l}\text { Mirqatul Mafatih Ali } \\
\text { Al Qari }\end{array}$ & 39 hadis & $\begin{array}{l}{[303][345][393][1239][1248][1254]} \\
{[1260][1268][1276][1355][1358][1374]} \\
{[1663][1704][1788][1799][1878][1890]} \\
{[1962][1965][2101][2915][3371][4246]} \\
{[4321][4322][4493][5058][5803][6107]} \\
{[6228][6520][7029][7050][7114][7215]} \\
{[7772][8028][8253]}\end{array}$ \\
\hline 10 & $\begin{array}{l}\text { Riyadhus Shalihin } \\
\text { Arab }\end{array}$ & 1 hadis & [430] \\
\hline 11 & $\begin{array}{l}\text { Shahih Ibnu Hibban } \\
\text { Arab }\end{array}$ & 4 hadis & [714] [2871] [3826] [8370] \\
\hline 12 & $\begin{array}{l}\text { Shahih Ibnu } \\
\text { Khuzaimah Arab }\end{array}$ & 3 hadis & [297] [308] [325] \\
\hline 13 & $\begin{array}{l}\text { Silsilah Shahihah } \\
\text { Albani }\end{array}$ & 5 hadis & [87] [178] [348] [1529] [2507] \\
\hline 14 & Sunan Baihaqi Shaghir & 2 hadis & {$[348][356]$} \\
\hline 15 & Sunan Tirmidzi & 1 hadis & {$[255]$} \\
\hline 16 & $\begin{array}{l}\text { Syarh Shahih Muslim } \\
\text { Nawawi }\end{array}$ & 12 hadis & $\begin{array}{l}{[624][632][641][716][719][724][750]} \\
{[1121][1123][1315][1504][2507]}\end{array}$ \\
\hline 17 & $\begin{array}{l}\text { Tamhid Ibnu Abdil } \\
\text { Barr }\end{array}$ & 4 hadis & [1500] [1874] [6078] [6079] \\
\hline 18 & $\begin{array}{l}\text { Targhib Wat Tarhib } \\
\text { Mundziri }\end{array}$ & 1 hadis & [174] \\
\hline 19 & Tuhfatul Ahwadzi & 16 hadis & $\begin{array}{l}{[568][623][667][670][1159][1206]} \\
{[1484][2950][3229][3406][3460][3854]} \\
{[4445][4562][4622][4624]}\end{array}$ \\
\hline
\end{tabular}

Pada kutubuttis'ah kata وسطيه tidak ditemukan satu haditspun yang menggunakan kata tersebut, sedangkan kata yang sepadan artinya dengan kata وسطيه yakni kata القعدال dan القصد dapan terdapat di beberapa kitab sebagai berikut:

Tabel 4 Pencarian lafad الَََْْْد pada kutubuttis'ah

\section{Nama Kitab}

Bukhori

Muslim

\section{Tabel 4 Pencarian lafad jasl pada kutubuttis'ah}

\section{Nomor Hadits}

5982

0

0 


$\begin{array}{ccc}\text { Abu Daud } & 0 & 0 \\ \text { Tirmidzi } & 0 & 0 \\ \text { Nasai } & 1 & 1288 \\ \text { Ibnu Majah } & 0 & 0 \\ \text { Ahmad } & 3 & 10261,10517,17605 \\ \text { Malik } & 0 & 0 \\ \text { Addarimi } & 0 & 0\end{array}$

Tabel 5 Pencarian lafad الإعتدال pada kutubuttis'ah

$\begin{array}{ccc}\text { Nama Kitab } & 0 & \text { Nomor Hadits } \\ \text { Bukhori } & 0 & \\ \text { Muslim } & 0 & \\ \text { Abu Daud } & 1 & 255 \\ \text { Tirmidzi } & 0 & \\ \text { Nasai } & 0 & \\ \text { Ibnu Majah } & 0 & \\ \text { Ahmad } & 0 & \\ \text { Malik } & 0\end{array}$

Dari hasil pencarian tersebut ditemukan sejumlah hadits, dari kitab hadits tersebut dicari lagi sesuai dengan tema Islam dan Moderasi beragama. Dari masing-masing kitab ditampilkan hadis-hadits yang cocok atau sepadan maknanya sebagai berikut:

1. Mengambil akar kata الْقَصند .

a. Bukhori Hadis No. 5982

Telah menceritakan kepada kami Adam telah menceritakan kepada kami Ibnu Abu Dzib dari Sa'id Al Maqburi dari Abu Hurairah radliallahu 'anhu dia berkata; Rasulullah shallallahu 'alaihi wasallam bersabda: "Salah seorang dari kalian tidak akan dapat diselamatkan oleh amalnya, " maka para sahabat bertanya; 'Tidak juga dengan engkau wahai Rasulullah? ' Beliau menjawab: 'Tidak juga saya, hanya saja Allah telah melimpahkan rahmat-Nya kepadaku. Maka beramallah kalian sesuai sunnah dan berlakulah dengan imbang, berangkatlah di pagi hari dan berangkatlah di sore hari, dan (lakukanlah) sedikit waktu (untuk shalat) di malam hari, niat dan niat maka kalian akan sampai."

b. Nasa'i Hadis No. 1288

Telah mengabarkan kepada kami Yahya bin Hubaib bin 'Arabi dia berkata; telah menceritakan kepada kami Hammad dia berkata; telah menceritakan kepada kami 'Atha bin As Saib dari Bapaknya, dia berkata; " Ammar bin Yasir pernah shalat bersama (mengimami) kami, dan ia mempersingkat shalatnya. Lalu sebagian orang bertanya kepadanya, 'Engkau telah meringankan -mempersingkat- shalat? ' Ia menjawab, 'Dalam shalat tadi aku memanjatkan doa dengan doa yang kudengar dari Rasulullah Shalallah 
'Alaihi Wa Sallam.' Lalu ia bangkit dan diikuti oleh seseorang -dia adalah Ubay, tetapi ia menyamarkan dirinya- lalu ia bertanya kepadanya tentang doa. Kemudian ia datang dan memberitahukan doa tersebut kepada kaumnya, 'Ya Allah dengan ilmu-Mu terhadap hal gaib dan kekuasaan-Mu atas makhluk, hidupkanlah aku selagi Engkau mengetahui bahwa hidup itu lebih baik bagiku, dan matikanlah aku jika Engkau mengetahui bahwa mati lebih baik bagiku. Ya Allah, aku memohon kepada-Mu rasa takut kepada-Mu saat nampak ataupun saat tidak nampak. Aku memohon kesederhanaan saat fakir dan kaya. Aku memohon kenikmatan tanpa habis dan kesenangan tanpa henti. Aku memohon keridhaan setelah adanya keputusan, dan kenyamanan hidup setelah mati dan kelezatan memandang kepada wajah-Mu serta keridhaan berjumpa dengan-Mu tanpa ada bahaya yang membahayakan dan tanpa fitnah yang menyesatkan. Ya Allah, hiasilah kami dengan hiasan iman dan jadikanlah kami orang yang menyampaikan hidayah dan yang mendapatkan hidayah."

c. Ahmad Hadis No. 10261

Telah menceritakan kepada kami Rauh, dia berkata; telah menceritakan kepada kami Ibnu Abu Dzib dari Al Maqburi dari Abu Hurairah, dia berkata; Rasulullah shallallahu 'alaihi wasallam bersabda: "Salah seorang dari kalian tidak dapat diselamatkan oleh amalnya;" para sahabat berkata; "Tidak juga dengan engkau wahai Rasulullah?" beliau bersabda: "Tidak juga dengan aku, hanya saja Allah melimpahkan rahmat-Nya kepadaku, maka beramal kalian sesuai sunnah dan berlakulah dengan imbang (tidak meremehkan dan tidak berlebihan), berangkatlah kalian di pagi dan sore, dan sedikit waktu (untuk shalat) di malam hari, berimbang dan berimbanglah maka kalian akan sampai."

d. Ahmad Hadis No. 10517

Telah menceritakan kepada kami Hasyim dari Ibnu Abu Dzib dari Al Maqburi dari Abu Hurairah dari Nabi shallallahu 'alaihi wasallam, beliau bersabda: "Salah seorang dari kalian tidak akan dapat diselamatkan oleh amalnya, " maka para sahabat bertanya, "Tidak juga dengan engkau wahai Rasulullah?" beliau menjawab: "Hanya saja Allah melimpahkan rahmat-Nya kepadaku. Maka beramal kalian sesuai sunnah dan berlakulah dengan imbang, berangkatlah di pagi hari dan berangkatlah di sore hari, dan (lakukanlah) sedikit waktu (untuk shalat) di malam hari, niat dan niat maka kalian akan sampai."

e. Malik Hadis No. 17605

Telah menceritakan kepada kami Ishaq Al Azraq dari Syarik dari Abu Hasyim dari Abu Mijlaz ia berkata, "Ammar pernah shalat bersama kami dan ia menunaikannya denan ringgkas, lalu orang-orang pun mengingkarinya. Maka Ammar bertanya, "Bukankah aku telah menyempurnakan rukuk dan sujud?" mereka menjawab, "Benar." Ammar berkata, "Sesungguhnya dalam dua rakaat itu, aku telah berdo'a dengan do'a yang Rasulullah shallallahu 'alaihi wasallam pernah berdo'a dengannya, 'allahumma bi'ilmikal ghaiba wa qudratika 'alal khalqi ahyinii maa 'alimtal hayaata khairan lii, watawaffanii idzaa kaanatil wafaatu khairan lii. Asaluka khasyyataka fil ghaib, wasy syahaadati wakalimatal haqqi fil ghadlabi war ridlaa wal qashda fil faqri wal ghinaa wa ladzdzatan nazhari ilaa wajhika wasy syauqi ilaa liqaaiika wa a'uudzu bika min dlarraaa mudlirratin wa min fitnatin 
mudlillatin, allahumma zayyinaa biziinatil iimaan, waj'alnaa hudaatan mahdiyyiin ( $Y a$ Allah, dengan ilmu-Mu atas yang ghaib, dan dengan kemahakuasaan-Mu atas seluruh makhluk, hidupkanlah aku jika Engkau mengetahui bahwa hidup lebih baik bagiku, dan matikanlah aku jika Engkau mengetahui bahwa kematian itu lebih baik bagiku. Ya Allah, sesungguhnya aku memohon pada-Mu agar aku takut pada-Mu dalam keadaan sembunyi atau ramai. Aku memohon pada-Mu agar dapat berkata dengan benar diwaktu ridla atau marah. Aku minta kepada-Mu agar dapat melaksanakan kesederhanaan dalam keadaan kaya atau fakir serta kenikmatan memandang wajah-Mu (di surga), rindu bertemu denganMu. Aku berlindung kepada-Mu dari penderitaan yang membahayakan dan fitnah yang menyesatkan. Ya Allah, hiasilah kami dengan iman, dan jadikanlah kami sebagai penunjuk (jalan) yang lurus yang memperoleh bimbingan dari-Mu). "' Telah menceritakan kepada kami Ahmad bin Abdul Malik Telah menceritakan kepada kami Muhammad bin Salamah dari Muhammad bin Ishaq dari Yazid bin Muhammad bin Khutsaim dari Muhammad bin Ka'ab Al Qurazhi telah menceritakan kepadaku Muhammad bin Khutsaim Abu Yazid dari Ammar bin Yasir ia berkata, "Aku dan Ali bin Abu Thalib radliallahu 'anhu adalah dua orang yang berteman pada saat perang Al Usyairah. Kemudian kami melewati sekelompok laki-laki dari Bani Mudlij yang sedang bekerja pada kebun kurma milik mereka...lalu ia menyebutkan makna hadits Isa bin Yunus."

2. Mengambil akar kata الإعتدال

a. Attirmidzi Hadis No. 255

Telah menceritakan kepada kami Hannad berkata; telah menceritakan kepada kami Abu Mu'awiyah dari Al A'masy dari Abu Sufyan dari Jabir bahwa Nabi shallallahu 'alaihi wasallam bersabda: "Apabila salah seorang dari kalian sujud hendaklah seimbangkan, dan jangan menelungkup kedua lengannya seperti menelungkupnya seekor anjing. " Ia berkata; "Dalam bab ini ada juga hadits dari Abdurrahman bin Syibl, Anas, Al Barra, Abu Humaid dan 'Aisyah." Abu Isa berkata; "Hadits Jabir ini derajatnya hasan shahih. Hadits ini diamalkan oleh para ahli ilmu, mereka memilih I'tidal (seimbang) ketika sujud dan memakruhkan posisi menelungkup sebagaimana binatang buas."

\section{Kajian Takhrij Hadits untuk Meneliti Kualitas dan Sanad Hadits}

Takhrij hadits merupakan sebuah ilmu untuk melacak dan mengetahui asal usul para perawi hadits dari sisi hubungannya dengan usaha periwayatan mereka terhadap hadits atau sebuah periwayatan hadits. Takhrij secara terminologis menurut Mahmud al-Tahhan (dalam Abdul Haris) mengartikan bahwa takhrij berarti menunjukkannya tempat hadits pada sumbersumbernya yang asli di mana hadits dikeluarkan dengan rangkaian periwayatannya (sanad), kemudian menjelaskan tingkat kualitasnya jika diperlukan. Sehingga M. Suyuti Ismail memberikan beberapa definisi, sebagai berikut:

a. Mengemukakan suatu hadits dengan menyebutkan sejumlah periwayat yang menyampaikan dalam spektrum sanad melalui rangkaian metode periwayatan yang ditempuh. Hal ini dapat dilihat dari para kolektor hadits, dimana memposisikan dirinya sebagai periwayat terakhir. 
b. Ulama atau Muhadditsin mengemukakan berbagai hadits yang telah diriwayatkan oleh guruguru hadits atau berbagai kitab hadits, sesuai dengan sistemikanya, atau gurunya dengan menerangkan atau mengungkapkan periwayatnya yang dikutip atau kitab hadits yang dijadikan rujukan.

c. Menunjukkan genealogi hadits dan mengemukakan sumber periwayatannya dari berbagai kitab hadits yang disusun oleh orang yang men-takhrij langsung sebagai kapasitasnya sebagai penghimpun kitab hadits (kolektor).

d. Mengemukakan hadits berdasarkan sumbernya atau berbagai sumber yang di dalamnya disertakan berbagai metode periwayatannya masing-masing. Sekalian dijelaskan konteks periwayatnya dan kualitas hadistnya.

e. Menunjukkan letak hadits pada sumbernya yang asli. Yaitu kitab yang menyebutkan sanad dan matan. ${ }^{8}$

1). Kitab Sahih Bukhori

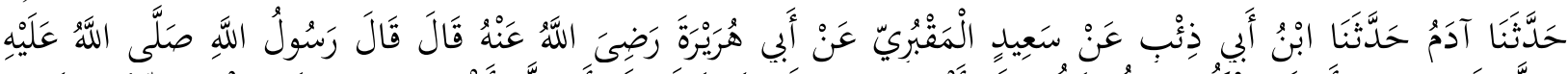

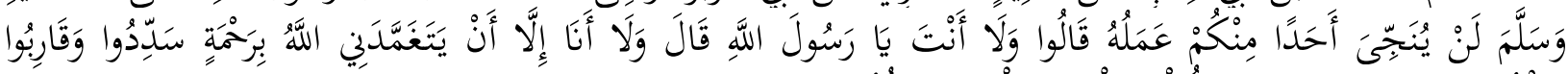

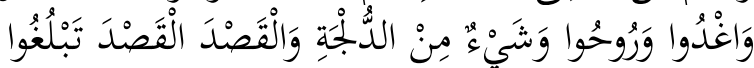

Jalur Periwayatan Hadits

Hadits tersebut diriwayatkan dari Adam bin Abu Ilyas, Abu Al-Hasan Hidup di Baghdad 220 H. Muhammad bin Abdur Rahman al Mughirah bin Al-Harits bin Al Dzi'b, Abu Al Harits hidup di Madinah 158 H. Sa'id bin Abi Said Kaisan kalangan tabiin kalangan pertengahan, Abu Sa'ad Hidup di Madinah wafat 123 H. Abdur Rahman bin Shakhir kalangan sahabat kuniyah Abu Hurairah hidup di Madinah dan Wafat $57 \mathrm{H}$.

2). Kitab Sunan Nasai

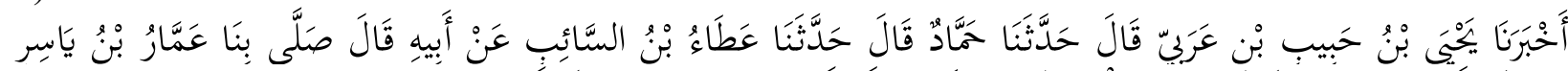

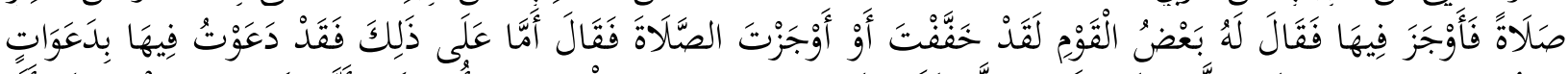

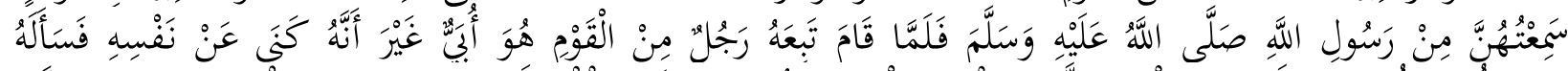

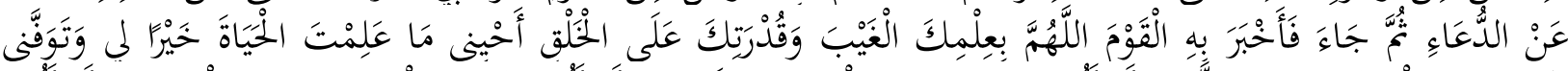

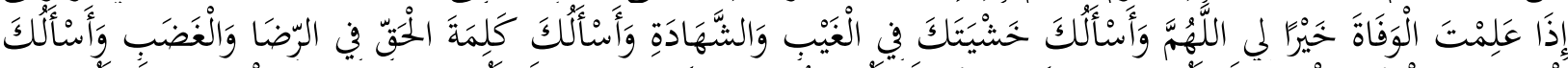

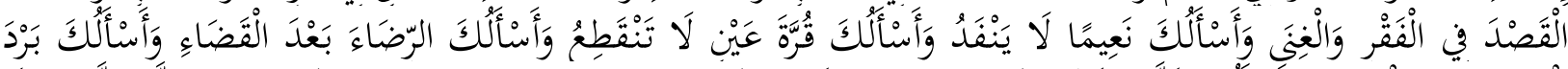

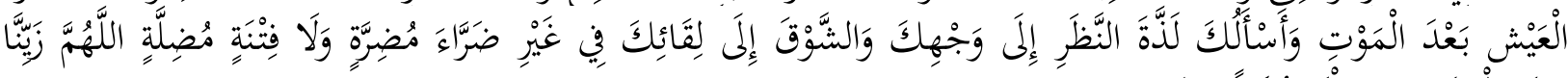

Jalur Periwayatan Hadits

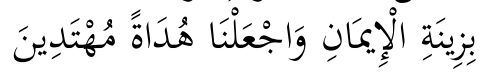

Hadits tersebut diriwayatkan dari ahya bin Habib bin 'Arabiy, Kalangan: Tabi'ul Atba' kalangan tua, Kuniyah: Abu Zakariya' hidup di Bashrah/Bashriy Wafat: 248 H. Hammad bin Zaid bin Dirham, Kalangan: Tabi'ut Tabi'in kalangan pertengahan, Kuniyah: Abu Isma'il, hidup di Bashrah. Wafat: 179 H. Atha' bin As Sa'ib bin Malik, Kalangan: Tabi'in kalangan biasa, Kuniyah: Abu As. Sa'ib hidup di: Kufah Wafat: 136 H. As Saa'ib bin Malik, Kalangan: Tabi'in

\footnotetext{
${ }^{8}$ Ali Akhbar Abaib Mas Rabbani Lubis, Ilmu Takhrij al-Hadits dalam Sorotan, Seputar PerkembanganPenggambaran Teori Dan Praktik (Pascasarjana IAIN Sunan Kalijaga).
} 
kalangan tua Kuniyah: Abu Yahya, hidup di Kufah. Ammar bin Yasir bin 'Amir bin Malik bin Kinanah bin Qays dari Kalangan Shahabat, Kuniyah: Abu Al Yaqzhan, hidup di: Kufah Wafat: $37 \mathrm{H}$

3) Kitab Imam Ahmad

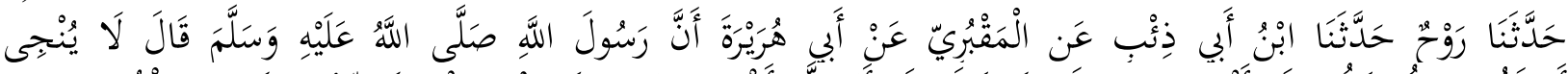

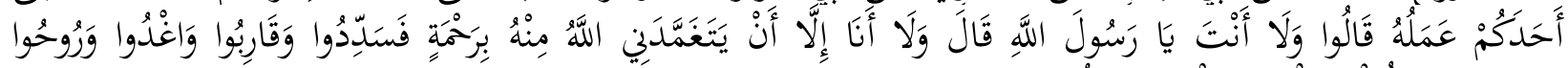

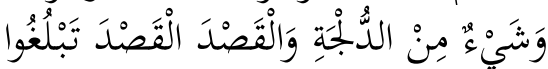

Jalur Periwayatan Hadits

Hadits tersebut diriwayatkan dari Rauh bin 'Ubadah bin Al 'Alaa' dari Kalangan Tabi'ut Tabi'in, kalangan biasa, Kuniyah Abu Muhammad, hidup di Bashrah, Wafat 205 H. Muhammad bin 'Abdur Rahman bin Al Mughirah bin Al Harits bin Abi Dzib, Kalangan Tabi'in kalangan biasa, Kuniyah Abu Al Harits, hidup di Madinah, Wafat 158 H. Sa'id bin Abi Sa'id Kaisan, Kalangan: Tabi'in kalangan pertengahan, Kuniyah: Abu Sa'ad, hidup di Madinah, Wafat: 123 H. Abdur Rahman bin Shakhr, Kalangan Shahabat, Kuniyah: Abu Hurairah, hidup di Madinah, Wafat 57 H.

4). Kitab Atturmidi

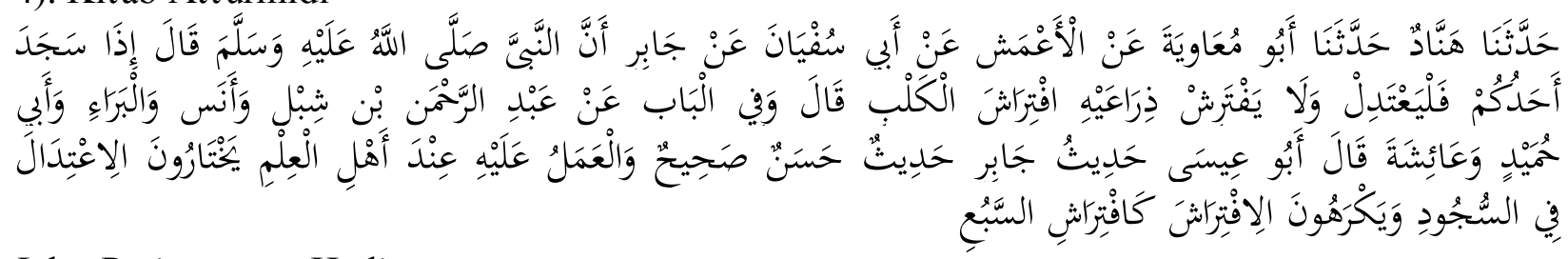

Jalur Periwayatan Hadits

Hadits tersebut diriwayatkan dari Hammam bin Yahya bin Dinar KalanganTabi'in (tdk jumpa Shahabat), KuniyahAbu 'Abdullah, hidup di Bashrah, Wafat 165 H. Qatadah bin Da'amah bin Qatadah, Kalangan Tabi'in kalangan biasa, Kuniyah Abu Al Khaththab, hidup di Bashrah, Wafat 117 H. Qaza'ah bin Yahya KalanganTabi'in kalangan pertengahan, Kuniyah Abu Al Ghadiyah, hidup di Bashrah. Abdullah bin 'Umar bin Al Khaththab bin Nufail Kalangan Shahabat, Kuniyah Abu 'Abdur Rahman, hidup di Madinah Wafat 73 H. Umar bin Al Khaththab bin Nufail Kalangan Shahabat, Kuniyah Abu Hafsh, hidup di Madinah, Wafat23 H.

\section{Kajian Tentang Kandungan Hadits Islam dan Moderasi Beragama}

a. Menilik makna keseimbangan (moderat) dalam hadits

Seperti penelusuran penulis bahwa kata وسطيه (moderat) tidak ditemukan dalam teks hadits, khususnya pada kitab كتب تسئه, beberapa kata yang sepadan dengan kata tersebut adalah dan الاعتدال dan.

Hadits Bukhori 5982, Nasai 1288, Ahmad 10261 dan 10517, dan Malik 17605, kata القصد dimaknai seimbang (imbang). Dari beberapa sumber menafsirkan kata القصد dimaknai dengan kata sabar. M. Quraish Shihab memandang bahwa kata sabar diartikan sebagai menahan baik dalam pengertian fisik materiil, seperti menahan seseorang dalam tahanan (kurungan) maupun inmaterial-non fisik seperti menahan diri (jiwa) dalam menghadapi sesuatu yang diinginkannya. 
Kemudian dari akar tersebut diperoleh sekian bentuk kata dengan arti yang beragam antara lain bermakna menjamin yaitu pemuka masyarakat yang melindungi kaumnya, atau berarti gunung yang tegar dan kukuh, awan yang berada di atas awan lainnya sehingga melindungi apa yang terdapat di bawahnya. Batu-batu yang kukuh, tanah yang gersang, sesuatu yang pahit atau menjadi pahit dan lain-lain. Maka dari sini ia menyimpulkan bahwa kesabaran menuntut ketabahan dalam menghadapi sesuatu yang sulit, berat, dan pahit yang harus diterima dan dihadapi penuh tanggung jawab. Jadi sabar adalah menahan diri atau membatasi jiwa dari keinginannya demi mencapai sesuatu yang baik atau lebih baik (luhur). ${ }^{9}$

\section{b. Konsep tawasuth dalam hadits}

Arti kata wasatiyah (moderat) secara terminology dapat dipahami sebagai suatu sikap atau perilaku yang senantiasa mengedepankan nilai-nilai jalan tengah dan tidak berlebih-lebihan. Moderat merupakan sikap toleran dan mengenal kompromi dalam melihat perbedaan. Namun hal ini bukan berarti tidak punya sikap sehingga membenarkan semua perbedaan tanpa mengenal batas. Hal ini tentu bukan sikap moderat, akan tetapi sikap melampaui kewajaran. Singkatnya wasathiyah adalah memilih jalan tengah dengan mengedepankan prinsip toleran, kompromi, dan tidak memaksakan kehendak dalam menetapkan suatu perkara yang berbeda. Sikap ini membawa kepada sikap lurus dan konsisten dalam mencari jalan tengah unt uk mengompromikan perbedaanperbedaan yang ada dalam berbagai aspek kehidupan umat manusia.

Istilah wasathiyah tidak ditemukan dalam teks-teks sunnah, namun bukan berarti sunnah tidak mengenal kata wasathiyah, akan tetapi dikenal dengan kata الاعتدال dang juga memiliki makna pertengahan. Penggunaan kata القصد dalam al-Qur'an digunakan oleh Lukman dalam menasihati anaknya:

Artinya:

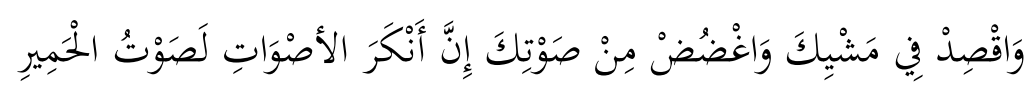

Dan sederhanalah kamu dalam berjalan dan lunakkanlah suaramu. Sesungguhnya seburukburuk suara ialah suara keledai (Luqman: 19).

Menurut Abu Hayyan Al-Andalusi dalam kitab Tafsir al-Bahr al-Muhit bahwa yang dimaksud kesederhanaan dalam berjalan adalah ketika berjalan hendaklah jangan terlalu cepat seperti orang yang dikejar ketakutan dan jangan pula terlalu lambat seperti orang sombong. ${ }^{10}$

Hadits nabi yang menyebut kata القصد yang bermakna pertengahan yaitu hadits yang diriwayatkan oleh Abu Hurairah dan diriwayatkan oleh Imam Bukhori (hadits ke 6463)

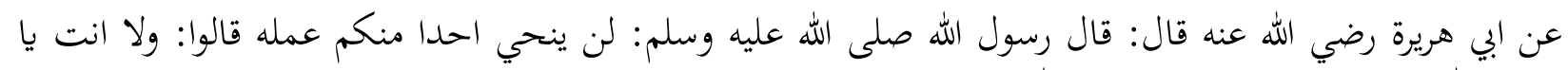

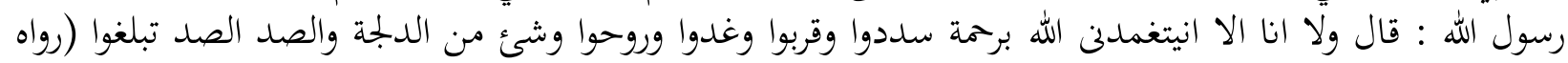
(البخارى )

Artinya:

Dari abu Hurairah ra berkata Rasulullah saw. bersabda: Amal seseorang tidak akan pernah menyelamatkannya, mereka bertanya: engkau juga wahai rasulullah? Beliau menjawab: begitu juga aku, kecuali bila Allah melimpahkan rahmat-Nya. Maka perbaikilah (niatmu)

\footnotetext{
${ }^{9}$ M. Idman Salewe, Sabar Dalam Hadis, Ma'had Aly As'adiyah Sengkang

${ }^{10}$ Ardiansyah, ISLAM WASATIYYAH DALAM PERSPEKTIF HADIS: Dari Konsep Menuju Aplikasi, (Mutawâtir: Jurnal Keilmuan Tafsir Hadis Volume 6, Nomor 2, Desember 2016).
} 
tetapi jangan berlebihan (dalam beramal sehingga menimbulkan bosan), bersegeralah di pagi dan siang hari. Bantulah itu dengan akhir-akhir waktu malam. Berjalanlah pertengahan berjalanlah pertengahan agar kalian mencapai tujuan. ${ }^{11}$

Sebagai suatu sistem, wasathiyah (القصد dalam terminologi hadits) memiliki prinsip dasar yang perlu diperhatikan. Yaitu:

1). Al-khairiyah (terpilih atau terbaik); makna inilah yang menurut al-Fakr al-Razi dianggap paling mewakili pengertian امة وسط: Dalam al-Qur'an surat al-Baqarah 143 dijelaskan:

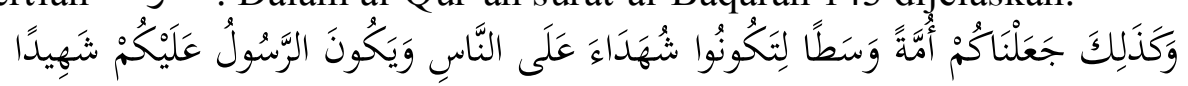

Artinya:

Dan demikian (pula) Kami telah menjadikan kamu (umat Islam), umat yang adil dan pilihan agar kamu menjadi saksi atas (perbuatan) manusia dan agar Rasul (Muhammad) menjadi saksi atas (perbuatan) kamu.

Makna terpilih ditegaskan dalam firman Allah surat Ali Imran 110:

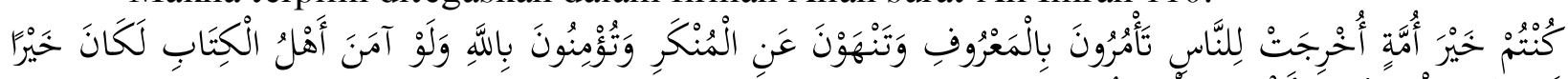

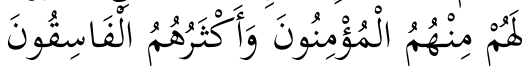

Artinya:

Kamu adalah umat yang terbaik yang dilahirkan untuk manusia, menyuruh kepada yang makruf, dan mencegah dari yang mungkar, dan beriman kepada Allah. Sekiranya Ahli Kitab beriman, tentulah itu lebih baik bagi mereka; di antara mereka ada yang beriman, dan kebanyakan mereka adalah orang-orang yang fasik.

Dengan kedua sikap itu, yaitu mengajak kedua umat manusia kepada kebaikan dan mencegah kemungkaran, ummat akan terpelihara dari kesesatan. Tugas inilah yang diemban oleh nabi dan rasul dalam berdakwah. Umat Islam menjadi pelopor kebaikan manakala melakoninya perannya dengan baik. Dalam menjalankan peran tersebut dibutuhkan kearifan dan kebijakan, sehingga membawa nilai-nilai kedamaian dan kelembutan. Hal tersebut telah dipraktikkan nabi dalam berdakwah di tengah-tengah kaumnya dengan simpatik, penuh kelembutan, dan kedamaian. Dakwah yang dijalani dengan penuh kelembutan dan simpatik serta tidak menggurui akan mampu menyentuh hati dan menjadikan rahmat bagi alam.

2). Al-'adalah (sikap adil), bersikap adil merupakan perintah Allah, sebagaimana dalam firma-

Nya surat al-Maidah ayat 8:

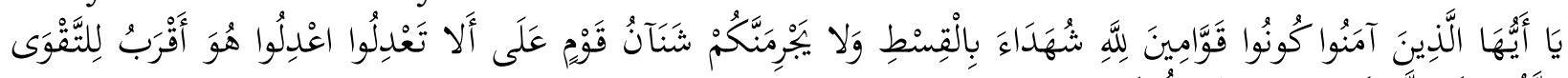

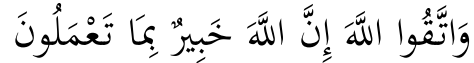

Artinya:

Hai orang-orang yang beriman, hendaklah kamu jadi orang-orang yang selalu menegakkan (kebenaran) karena Allah, menjadi saksi dengan adil. Dan janganlah sekali-kali kebencianmu terhadap sesuatu kaum, mendorong kamu untuk berlaku tidak adil. Berlaku adillah, karena adil itu lebih dekat kepada takwa. Dan bertakwalah kepada Allah, sesungguhnya Allah Maha Mengetahui apa yang kamu kerjakan".

\footnotetext{
${ }^{11}$ Muhammad bin Ismail bin Ibrahim al Mughirah Abu Abdullah al-Bukhari, Al-Jamius Shahih hadits no 6463, Vol 8 (Kairo: Dar al-Shu'b, 1987), hlm. 122.
} 
Keadilan wajib ditegakkan baik bersifat di dalam (internal) maupun di luar (ekternal). Maka Wasatiyah ditafsirkan nabi dengan kata adil sebagaimana keterangan Abu Sa'id Alkhudri. Adapun konsep keadilan di dalam al-Qur'an dapat ditemukan dari mulai yang bermakna tauhid sampai keyakinan mengenai hari kebangkitan Kepemimpinan dan permasalahan muamalah seperti ekonomi dan jual beli. Keadilan juga mempunyai makna yang bermacammacam, keadilan dalam kepercayaan, yakni tidak berbuat syirik, (Q.S. Lukman ayat 13). keadilan dalam rumah tangga dengan memberikan kehidupan yang layak dan berbuat yang terbaik (Q.S. al-baqarah: 282-283); keadilan dalam perjanjian dan keadilan hukum.

3). Al-Tawazun (kesimbangan). Al-Tawazun memiliki arti memberikan sesuatu akan haknya, tanpa ada penambahan dan pengurangan, dan keseimbangan tidak akan tercapai tanpa kedisiplinan (QS. Arrahman: 7). Salah satu yang menjadikan Islam sebagai agama yang sempurna adalah karena keseimbangan antara urusan duniawi dan ukhrawi. Keseimbangan merupakan keharusan social. Dengan demikian seseorang yang tidak seimbang kehidupan individu dan sosialnya maka tidak akan sempurna individu dan sosialnya.

4). Attasamuh (toleran). Tasamuh adalah tenggang rasa atau sikap saling menghargai dan menghormati terhadap sesama, baik sesame muslim maupun nonmuslim, dan tidak mementingkan diri sendiri serta tidak memaksakan kehendak.

5). Al-Istiqamah (Konsistensi). Konsistensi dalam membela kebenaran dan menghindarkan diri dari kemungkaran dan penyimpangan. Prinsip ini menjadi penting di tengah kehidupan yang menggoda dan menggiurkan saat ini.

6). Raf al-halaj (menghilangkan kesulitan); Islam adalah agama dengan ajaran yang mudah, sebab Allah menghendaki kemudahan dan tidak mempersulit hamba-hamba-Nya. Agama bukanlah ajaran yang memberatkan bagi manusia, sebaliknya hidup lebih terarah. Hal ini ditegaskan dalam surat al-Baqarah 185:

Artinya:

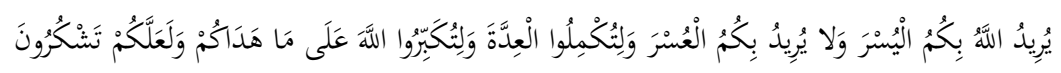

Allah menghendaki kemudahan bagimu, dan tidak menghendaki kesukaran bagimu. Dan hendaklah kamu mencukupkan bilangannya dan hendaklah kamu mengagungkan Allah atas petunjuk-Nya yang diberikan kepadamu, supaya kamu bersyukur.

\section{Kesimpulan}

وسطيه yang berarti moderat. Kalimat yang semakna dengan kata وسطيه adalah الاعندال danana kata terdapat dalam kitab Bukhari sebanyak satu kali yaitu hadits ke 5982, Kitab Nasai sebanyak satu kali yaitu hadits ke 1288, dan didalam kitab Ahmad sebanyak tiga kali yaitu hadits ke 10261, 10517, 17605. Sedangkan kata الاعتدال hanya terdapat pada hadits Tirmidzi hadits ke 255.

Prinsip wasathiyah yang diterangkan dalam hadits adalah Al-khairiyah (terpilih atau terbaik), Al-'adalah (sikap adil), Al-Tawazun (kesimbangan). Attasamuh(toleran). Al-Istiqamah (Konsistensi), Raf al-halaj (menghilangkan kesulitan). 


\section{DAFTAR PUSTAKA}

\section{Buku}

Al-Ghazali, Muhammad, Qudza'if al-Haqq, cet ke-1, (Dimisyqa: Dar al Qalam, 1991),

Departemen Agama Republik Indonesia, Al-Qur'an Al-Karim

Muhammad bin Ismail bin Ibrahim al Mughirah Abu Abdullah al-Bukhari, Al-Jamius Shahih hadits no 6463, Vol 8 (Kairo: Dar al-Shu'b, 1987)

Nurcholis, Ahlussunnah Wal Jama'ah Dan Nahdlatul Ulama. (Tulungagung: PC NU KAB. Tulungagung, 2011),

Siddiq, Achmad, Khittoh Nahdliyin Cet. III, (Surabaya: Khalista LTNU, 2005)

Thoha, As'ad, Pendidikan Aswaja dan ke-NU-an untuk MA/SMA/SMK kelas 12 Kurikulum 2012, (Jawa Timur: PWLP Ma'arif NU 2013)

\section{Artikel Jurnal}

Akhmadi, Agus, Moderasi Beragama Dalam Keragaman Indonesia, Jurnal Diklat Keagamaan, Vol. 13, no. 2, Pebruari - Maret 2019

Al-Mubârak b. Muhammad al-Jazarî Majd al-Dîn Abû al-Sa‘âdât b. al-Athîr, Jâmi` alUsûl fî Ahâdîth al-Rasûl, ed. 'Abd al-Qâdir al-Arnaût, Vol. 10 (Beirut: Maktabah Dâr alBayân, 1972),

Ardiansyah, ISLAM WASATIYYAH DALAM PERSPEKTIF HADIS: Dari Konsep Menuju Aplikasi, (Mutawâtir: Jurnal Keilmuan Tafsir Hadis Volume 6, Nomor 2, Desember 2016).

\section{Prosiding}

Institusional Repository of IAIN Tulungagung, Implementasi Nilai At-Tawasuth (Moderat) Ahlussunnah Wal Jamaah dalam Pendidikan Karakter di MA Aswaja Ngunut Tulungagung.

Salewe, M. Idman, Sabar Dalam Hadis, Ma'had Aly As'adiyah Sengkang.

Yusuf, Achmad, Moderasi Islam dalam Dimensi Trilogi Islam (Akidah, Syariah, Dan Tasawuf), Jurnal al-Murabbi, Volume 3 Nomor 1, Juni 2018 